\title{
Evaluation of Recovery Profiles of Different Anesthetic Techniques for Ambulatory Anorectal Surgery: A Comparative Study
}

\author{
Atanu Mukherjee ${ }^{1}$, Gagandeep Singh ${ }^{2}$ \\ ${ }^{1}$ Assistant professor, Department of Anesthesiology, Muzaffarnagar Medical College, Muzaffarnagar, Uttar Pradesh, India, ${ }^{2}$ Associate Professor, \\ Department of Anesthesiology, Muzaffarnagar Medical College, Muzaffarnagar, Uttar Pradesh, India.
}

\section{Abstract}

Background: Ambulatory surgery encompasses those surgical interventions that are more complex than office-based procedures performed under local anaesthesia but fewer complexes than major procedures requiring at least an overnight stay. Hence; we planned the present study to assess the recovery profiles of different anesthetic techniques for ambulatory anorectal surgery. Subjects and Methods: A total of 90 subjects were included in the present study who were about to undergo anorectal surgery. Random division of all the patients was done into three study groups: Group 1- Patients undergoing ambulatory anorectal surgery under spinal anesthesia, Group 2- Patients undergoing ambulatory anorectal surgery under local anesthesia, and Group 3- Patients undergoing ambulatory anorectal surgery under general anesthesia. All the subjects were prepared for surgical procedure. According to their respective groups, all the surgeries were performed. A master chart was prepared, where recovery profile of all the subjects was recorded and compared. All the results were analyzed by SPSS software. Results: Mean duration of anesthesia among subjects of group 1, group 2 and group 3 was 74.5 minutes, 43.8 minutes and 79.1 minutes respectively. Mean duration of surgery among the subjects of group 1, group 2 and group 3 was 27.5 minutes, 26 minutes and 26.5 minutes respectively. Mean duration of hospital stay among subjects of group 1, group 2 and group 3 was 260.4 minutes, 131.8 minutes and 255.3 minutes respectively. In the present study, recovery profile of local anesthesia was significantly faster in comparison to the recovery profile of general and spinal anesthesia.Conclusion: Local anesthesia is the most effective technique in terms of recovery profile in patients undergoing ambulatory anorectal surgeries.

Keywords: Ambulatory, Anorectal, Anesthesia.

Corresponding Author: Dr Atanu Mukherjee, Assistant professor, Department of Anesthesiology, Muzaffarnagar Medical College, Muzaffarnagar, Uttar Pradesh, India.

Received: July 2019

Accepted: July 2019

\section{Introduction}

Minor anorectal diseases are rather common. The prevalence of hemorrhoids and other anorectal diseases is $4-5 \%$ in adult population in the United States; approximately $10 \%$ of the cases require an operation. According to Argov, internal hemorrhoids are present in 4 percent of Western adult population. Published data about the prevalence of minor anorectal diseases inLithuania is not available. In the year 2001, 337 anorectal operations were performed in the Department of Surgery of Kaunas University of Medicine Hospital, 146 (43.32\%) of them were hemorrhoidectomies. ${ }^{[1-}$ ${ }^{3]}$ Ambulatory surgical procedures should be performed in a setting with adequate personnel and equipment to provide a safe procedure, anesthesia, and recovery. This includes freestanding ambulatory surgery centers (ASCs) as well as hospital-based outpatient surgery departments which appear to perform equally well. ${ }^{[4-6]}$ Reasons cited for improved performance of freestanding ASCs may include increased volume for specific procedures, newer facilities, and improved staffing. Hospital-based outpatient surgery departments may have benefits derived from their hospital relationship, including greater resources of equipment and specialists. ${ }^{[7]}$

Hence; we planned the present study to assess the recovery profiles of different anesthetic techniques for ambulatory anorectal surgery.

\section{Subjects and Methods}

The present study was planned in the Anesthesia department and it included evaluation and comparison of recovery profiles of different anesthetic techniques for ambulatory anorectal surgery. A total of 90 subjects were included in the present study who were about to undergo anorectal surgery. Random division of all the patients was done into three study groups: Group 1- Patients undergoing ambulatory anorectal surgery under spinal anesthesia, Group 2- Patients undergoing ambulatory anorectal surgery under local anesthesia, and Group 3- Patients undergoing ambulatory anorectal surgery under general anesthesia. Inclusion criteria for the present study included:

- Subjects with negative history of any known drug allergy 
- Subjects with negative history of diabetes and hypertension

- Subjects with negative history of presence of any form of malignancy

All the subjects were prepared for surgical procedure. According to their respective groups, all the surgeries were performed. A master chart was prepared, where recovery profile of all the subjects was recorded and compared. All the results were analysed by SPSS software. Chi- square test was used for assessment of level of significance. P- value of less than 0.05 was taken as significant.

\section{Results}

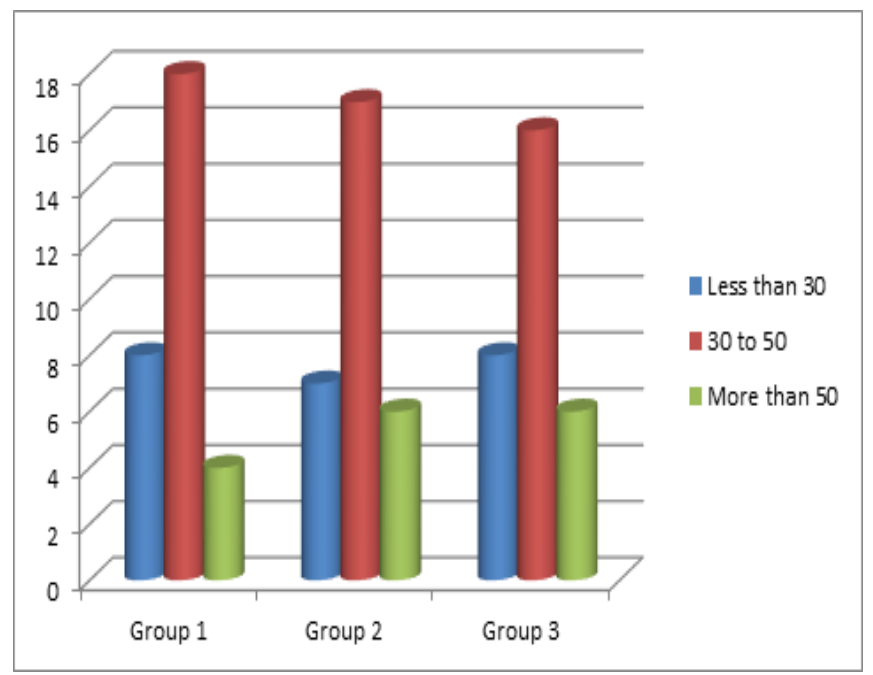

Figure 1: Age-wise distribution of patients

Table 1: Demographic data

\begin{tabular}{|l|l|l|l|}
\hline Parameter & Group 1 & Group 2 & Group 3 \\
\hline Mean weight $(\mathrm{Kg})$ & 77.2 & 79.5 & 80.2 \\
\hline Males & 22 & 24 & 23 \\
\hline Females & 8 & 6 & 7 \\
\hline
\end{tabular}

Table 2: Recovery profile among subjects of different groups

\begin{tabular}{|l|l|l|l|}
\hline Parameter & Group 1 & Group 2 & Group 3 \\
\hline Duration of anesthesia (minutes) & 74.5 & 43.8 & 79.1 \\
\hline Duration of surgery (minutes) & 27.5 & 26 & 26.5 \\
\hline Duration of hospital stay (minute) & 260.4 & 131.8 & 255.3 \\
\hline
\end{tabular}

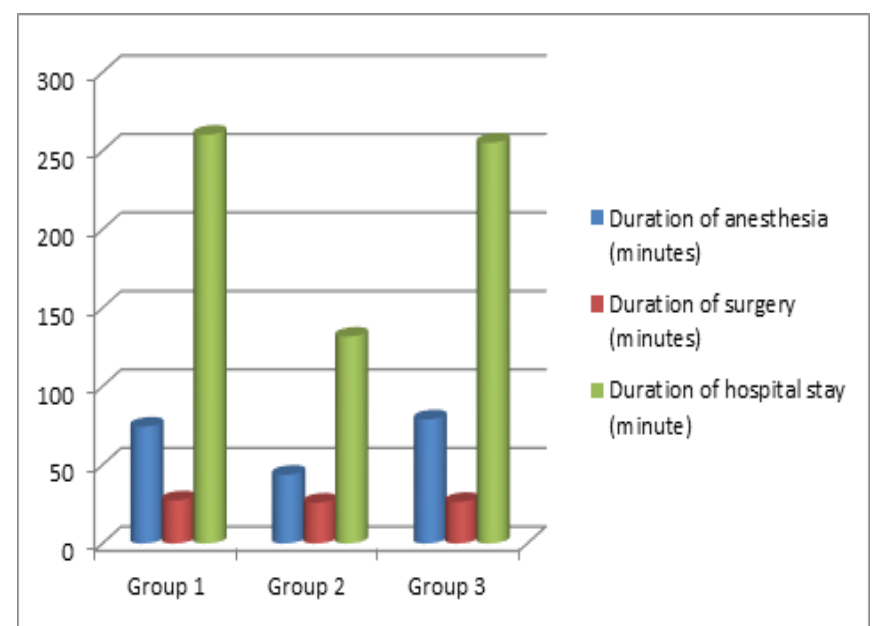

Figure 2: Recovery profile among subjects of different groups

\begin{tabular}{|c|c|c|c|}
\hline \multicolumn{4}{|c|}{ Table 3: Comparison of recovery profile } \\
\hline Parameter & $\begin{array}{l}\text { p- value } \\
\text { (Group 1 vs } \\
\text { Group 2) }\end{array}$ & $\begin{array}{l}\text { p- value } \\
\text { (Group } 1 \text { vs } \\
\text { Group 3) }\end{array}$ & $\begin{array}{l}\text { p- value } \\
\text { (Group } 2 \text { vs } \\
\text { Group 3) }\end{array}$ \\
\hline $\begin{array}{l}\text { Duration of } \\
\text { anesthesia } \\
\text { (minutes) }\end{array}$ & $0.00^{*}$ & 0.52 & $0.02 *$ \\
\hline $\begin{array}{l}\text { Duration of } \\
\text { surgery (minutes) }\end{array}$ & 0.26 & 0.12 & 0.71 \\
\hline $\begin{array}{l}\text { Duration of } \\
\text { hospital stay } \\
\text { (minute) }\end{array}$ & $0.00 *$ & 0.23 & $0.00 *$ \\
\hline
\end{tabular}

In the present study, analysis of a total of 90 patients was done. 18 patients in group 1, 17 patients in group 2 and 16 patients in group 3 belonged to the age group of 30 to 50 years. Mean age of the patients of Group 1, Group 2 and Group 3 was 48.5, 46.8 and 47.2 years respectively. Mean weight of the subjects of group 1, group 2 and group 3 was $77.2 \mathrm{Kg}, 79.5 \mathrm{Kg}$ and $80.2 \mathrm{Kg}$ respectively. There were 22 males, 24 males and 23 males in group 1, group 2 and group 3 respectively. In the present study, mean duration of anesthesia among subjects of group 1, group 2 and group 3 was 74.5 minutes, 43.8 minutes and 79.1 minutes respectively. Mean duration of surgery among the subjects of group 1, group 2 and group 3 was 27.5 minutes, 26 minutes and 26.5 minutes respectively. Mean duration of hospital stay among subjects of group 1, group 2 and group 3 was 260.4 minutes, 131.8 minutes and 255.3 minutes respectively. In the present study, recovery profile of local anesthesia was significantly faster in comparison to the recovery profile of general and spinal anesthesia.

\section{Discussion}

Ambulatory surgery encompasses those surgical interventions that are more complex than office-based procedures performed under local anaesthesia but fewer complexes than major procedures requiring at least an overnight stay. The widespread growth of ambulatory procedures requires changes in the clinical anesthesia practice. Economic and social pressures have changed surgeons and anesthesiologists views. Approximately $60 \%$ to $70 \%$ of all elective procedures in the USA and some European countries, and around 50\% in Brazil, are currently performed in outpatient settings. Conventional spinal anesthesia may be undesirable for such procedures due to prolonged lower limb motor block with consequent change to unplanned hospital admission. ${ }^{[8,9]}$

In the present study, analysis of a total of 90 patients was done. 18 patients in group 1, 17 patients in group 2 and 16 patients in group 3 belonged to the age group of 30 to 50 years. Mean age of the patients of Group 1, Group 2 and Group 3 was 48.5, 46.8 and 47.2 years respectively. Mean weight of the subjects of group 1, group 2 and group 3 was $77.2 \mathrm{Kg}, 79.5 \mathrm{Kg}$ and $80.2 \mathrm{Kg}$ respectively. There were 22 males, 24 males and 23 males in group 1, group 2 and group 3 respectively. Song D et al compared the cost-effectiveness of an ilioinguinal-hypogastric nerve block (IHNB) technique with standardized general and spinal anesthetics techniques for inguinal herniorrhaphy in the ambulatory setting. They randomly assigned 81 consenting outpatients to receive IHNB- monitored anesthesia care (MAC), general 
anesthesia, or spinal anesthesia. They evaluated recovery times, 24-h postoperative side effects and associated incremental costs. Compared with general and spinal anesthesia, patients receiving IHNB-MAC had the shortest time-to-home readiness, lowest pain score at discharge, and highest satisfaction at 24-h follow-up. The total anesthetic costs were also the least in the IHNB-MAC group. They concluded that IHNB-MAC is the most cost-effective anesthetic technique for outpatients undergoing unilateral inguinal herniorrhaphy with respect to speed of recovery, patient comfort, and associated incremental costs. ${ }^{[10]}$

In the present study, mean duration of anesthesia among subjects of group 1, group 2 and group 3 was 74.5 minutes, 43.8 minutes and 79.1 minutes respectively. Mean duration of surgery among the subjects of group 1, group 2 and group 3 was 27.5 minutes, 26 minutes and 26.5 minutes respectively. Mean duration of hospital stay among subjects of group 1, group 2 and group 3 was 260.4 minutes, 131.8 minutes and 255.3 minutes respectively. In the present study, recovery profile of local anesthesia was significantly faster in comparison to the recovery profile of general and spinal anesthesia. Tang $\mathrm{J}$ et al compared the clinical effects, recovery characteristics, and cost-effectiveness of propofol and sevoflurane when used alone or in combination for office-based anesthesia. One hundred four outpatients undergoing superficial surgical procedures at an office-based surgical center were randomly assigned to one of three general anesthetic groups. In groups I and II, propofol 2 $\mathrm{mg} / \mathrm{kg}$ was administered for induction followed by propofol 75-150 microg x $\mathrm{kg}(-1) \mathrm{x} \min (-1)$ (group I) or sevoflurane 1$2 \%$ (group II) with $\mathrm{N} 2 \mathrm{O} 67 \%$ in oxygen for maintenance of anesthesia In group $\mathrm{m}$, anesthesia was induced and maintained with sevoflurane in combination with $\mathrm{N} 2 \mathrm{O} 67 \%$ in oxygen. Although early recovery variables (e.g., eye opening, response to commands, and sitting up) were similar in all three groups, the times to standing up and to be "home ready" were significantly prolonged when sevoflurane- $\mathrm{N} 2 \mathrm{O}$ was used for both induction and maintenance of anesthesia. The time to tolerating fluids, recovery room stay, and discharge times were significantly decreased when propofol was used for both induction and maintenance of anesthesia. Similarly, the incidence of postoperative nausea and vomiting and the need for rescue antiemetics were also significantly reduced after propofol anesthesia. Finally, the total costs and patient satisfaction were more favorable when propofol was used for induction and maintenance of officebased anesthesia Compared with sevoflurane-N2O, use of propofol-N2O for office-based anesthesia was associated with an improved recovery profile, greater patient satisfaction, and lower costs. ${ }^{[1]}$

\section{Conclusion}

From the above results, it can be concluded that use of local anesthesia is the most effective technique in terms of recovery profile in patients undergoing ambulatory anorectal surgeries. However; further studies are recommended.

\section{References}

1. Li S, Coloma M, White PF, Watcha MF, Chiu JW, Li H, Huber PJ. Comparison of the costs and recovery profiles of three anesthetic techniques for ambulatory anorectal surgery. Anesthesiology 2000;93(5):1225-30.

2. Argov S. Radical ambulatory hemorrhoidectomy. Harefuah 1994;126(4):189-91, 239.

3. Smith LE. Ambulatory surgery for anorectal diseases: an update. South Med J 1986;79(2):163-6

4. Li S, Coloma M, White PF, Watcha MF, Chiu JW, Li H, Huber PJ. Comparison of the costs and recovery profiles of three anesthetic techniques for ambulatory anorectal surgery. Anesthesiology 2000;93(5):1225-30.

5. Gupta A1, Axelsson K, Thörn SE, Matthiessen P, Larsson LG, Holmström B, Wattwil M. Low-dose bupivacaine plus fentanyl for spinal anesthesia during ambulatory inguinal herniorrhaphy: a comparison between $6 \mathrm{mg}$ and 7. $5 \mathrm{mg}$ of bupivacaine. Acta Anaesthesiol Scand. 2003 Jan;47(1):13-9.

6. Lin JK. Preservation of anal sphincter function after hemorrhoidectomy under local anesthesia. Zhongua Yi XueZaZhi 2001;64(9):519-24.

7. Place R, Hyman N, Simmang C. et al. Practice parameters for ambulatory anorectal surgery. Dis Colon Rectum. 2003;46(5):573-576.

8. Gudaityte J1, Marchertiene I, Pavalkis D. Anesthesia for ambulatory anorectal surgery. Medicina (Kaunas). 2004;40(2):101-11.

9. Sungurtekin H1, Sungurtekin U, Erdem E. Local anesthesia and midazolam versus spinal anesthesia in ambulatory pilonidal surgery. $\mathrm{J}$ ClinAnesth. 2003 May;15(3):201-5.

10. Song D1, Greilich NB, White PF, Watcha MF, Tongier WK. Recovery profiles and costs of anesthesia for outpatient unilateral inguinal herniorrhaphy. AnesthAnalg. 2000 Oct;91(4):876-81.

11. Tang J1, Chen L, White PF, Watcha MF, Wender RH, Naruse R, Kariger R, Sloninsky A. Recovery profile, costs, and patient satisfaction with propofol and sevoflurane for fast-track office-based anesthesia. Anesthesiology. 1999 Jul;91(1):253-61.

Copyright: (C) the author(s), publisher. Academia Anesthesiologica Internationalis an Official Publication of "Society for Health Care \& Research Development". It is an open-access article distributed under the terms of the Creative Commons Attribution Non-Commercial License, which permits unrestricted non-commercial use, distribution, and reproduction in any medium, provided the original work is properly cited.

How to cite this article: Mukherjee A, Singh G.Evaluation of Recovery Profiles of Different Anesthetic Techniques for Ambulatory Anorectal Surgery: A Comparative Study.Acad. Anesthesiol. Int. 2019;4(2):64-66.

DOI: dx.doi.org/10.21276/aan.2019.4.2.17

Source of Support: Nil, Conflict of Interest: None declared. 